\title{
Rituais Fúnebres no Processo do Luto: Significados e Funções
}

\author{
Christiane Pantoja de Souza \& Airle Miranda de Souza \\ Universidade Federal do Pará, Belém, PA, Brasil
}

\begin{abstract}
RESUMO - Os estudos acerca dos rituais humanos têm mostrado que as mudanças ao longo da vida, incluindo a morte de entes queridos, precisam ser marcadas, pontuadas, de forma que estes acontecimentos recebam a consideração necessária. Neste estudo, são abordados os significados e funções dos rituais fúnebres como benignos para a elaboração da perda por morte de uma pessoa significativa. Sustenta-se que o caráter expressivo dos rituais possibilita descrever o que não se consegue expressar em palavras, estimulando o trabalho de luto e desempenhando importante função de maturação social e psicológica diante da perda. Possibilita também a contextualização da experiência da perda, oferecendo à família enlutada o suporte de pertencer a uma cultura e a uma compreensão compartilhada sobre a morte.
\end{abstract}

PALAVRAS-CHAVE: ritual, morte, luto

\section{Funeral Rituals in The Process of Mourning: Meaning and Functions}

\begin{abstract}
The studies about human rituals have shown that changes throughout life, including the death of loved ones, need to be marked, receiving the necessary consideration. In this study, the meanings and the functions of funeral rituals are approached as resources for the elaboration of the death of a significant person. It is sustained that the expressive character of the rituals allows to describe what we can not express in words, stimulating the work of mourning and exerting an important role to the social and psychological maturity at the loss. It also allows the contextualization the loss experience, while offering to the bereaved family the support to be part of the culture and a shared understanding of death.
\end{abstract}

KEYWORDS: ritual, death, mourning

Todos os povos ritualizam seus mortos e apresentam maneira similar de reação diante da perda por morte de um ente querido (Imber-Black, 1998; Schilindwein, 2001). Há registros arqueológicos sobre práticas rituais fúnebres desde a Pré-História, sugerindo que a emergência da consciência coincidiu com a emergência de uma preocupação com relação à finitude, através do cuidado ritualizado para com entes queridos mortos (Leakey, 1997).

A importância de se estudar o ritual fúnebre reside na possibilidade de se compreender as implicações das manifestações humanas diante da morte para a vida dos indivíduos e da sociedade, visto que este tema se encontra intimamente relacionado à forma como as pessoas significam o tema da morte e do morrer e como elaboram perdas por morte. Tal compreensão implica, portanto, que se tenha mais subsídios teóricos que contribuam com a fundamentação das práticas de suporte aos enlutados, sendo estas práticas pensadas como medidas preventivas para as complicações possíveis, como o luto crônico, o luto adiado, transtornos psiquiátricos ou manifestações psicossomáticas.

O tema do ritual está intimamente ligado ao modo como as pessoas resolvem as questões relativas ao próprio desenrolar da vida social do qual a morte faz parte. Neste sentido, entende-se que a forma de ritualização de uma sociedade revela como essa sociedade se organiza e reorganiza diante das mudanças e como ela simboliza esses momentos. Portanto, pensar em ritual fúnebre é tratar do sofrimento psíquico, com sérias implicações para a saúde mental dos indivíduos e para a vida social.

Os estudos acerca dos rituais humanos (Ariès, 2003; Augras, 1984; Bayard, 1996; Bromberg, 2000; Cunha, 1999; Deweik, 2007; Gennep, 1978; Gorer, 1955; ImberBlack, 1998; Kovács, 1992, 2003, 2005; Kübler-Ross, 1987; Maranhão, 1987; Mitford, 1963; Schlindwein, 2001; Souza, 2008), incluindo o ritual fúnebre, têm mostrado que mudanças ao longo da vida precisam ser marcadas,

\footnotetext{
*E-mail: tianepantoja@gmail.com

- Submetido: 21/03/2016; Aceito: 12/10/2016; Revisado: 05/01/2017.
} 
pontuadas, e que as práticas rituais tendem a ajudar a simbolizar essas mudanças e elaborar as perdas associadas.

Este estudo nasceu da experiência clínica e hospitalar no atendimento a pacientes em luto por vários tipos de perdas, dentre as quais, a perda por morte. A experiência de atendimento a pessoas enlutadas nos levou a identificar que estes pacientes trazem para o consultório manifestações que dizem respeito a um sentido ritualístico ou de ritualização diante de suas perdas. Essas manifestações podem ser observadas através dos relatos dos pacientes sobre a visita ao cemitério, ou através de outras manifestações como, por exemplo, uma carta escrita para a pessoa morta, como ocorreu com uma paciente que apresentou espontaneamente sua produção na sessão de psicoterapia. Tais manifestações nos alertaram para o lugar que a ação ritual ocupa diante de uma perda por morte e suas implicações, no sentido do paciente significar suas perdas.

$\mathrm{O}$ atendimento a pessoas enlutadas desvelou a necessidade de considerarmos o ritual fúnebre como uma categoria importante de análise nas condições de luto e na elaboração de uma perda por morte, visto que as reações humanas diante da morte abrangem cuidados dispensados ao cadáver e outros procedimentos muitas vezes longos e minuciosos realizados nos rituais fúnebres, chamando a atenção para o que poderiam significar esses cuidados, visto que são dispensados ao corpo já sem vida.

Portanto, a partir da compreensão de que ao longo do ciclo de vida vivenciamos perdas por morte de entes queridos e de que é importante marcar estes acontecimentos, dando a eles a consideração necessária, este estudo teve por objetivo abordar os significados e funções dos rituais fúnebres no processo de luto, considerando sua importância na elaboração da perda por morte de pessoas significativas.

Para alcançar o objetivo proposto, foi realizado um levantamento bibliográfico que levou em consideração a literatura sobre rituais e seus sentidos de passagem, bem como os estudos sobre luto. Os resultados foram organizados e trabalhados nas sessões componentes do estudo.
Na primeira sessão, denominada Ritos Fúnebres: Ação e símbolos, foi trabalhada a ação simbólica do procedimento de ritualização a partir da compreensão encontrada na literatura antropológica sobre o tema, com ênfase nos ritos fúnebres.

Na segunda sessão, denominada Rito e ritual: Sobre significados, discutiu-se acerca dos significados dos termos rito e ritual, a partir da utilização que esses termos recebem no dicionário e em obras de referência na literatura antropológica (Gennep, 1978; Rivière, 1997; Turner, 1974).

A terceira sessão, denominada $O$ sentido de passagem no ritual, tratou especificamente de noções referentes à passagem, como no caso da noção de limiar, pois compreende-se que os indivíduos modificam-se ao atravessarem a fronteira em cada etapa e nisso se assemelham as cerimônias de nascimento, infância, puberdade, noivado, casamento, gravidez, paternidade, iniciação religiosa e funerais.

A quarta sessão, denominada Os Rituais e suas funções no processo de luto, tratou dos rituais fúnebres como demarcadores de um estado de enlutamento, com função simbólica de reconhecimento da importância da perda e da importância daquele ente que foi perdido, marcando, pontuando, revelando e significando o acontecimento, de acordo com a crença de cada cultura, contribuindo para o processo de luto necessário diante de perdas importantes.

A quinta e última sessão, denominada Significar a perda na sociedade do interdito da morte, abrangeu o paradoxo atual implicado no tema da morte, pois ao mesmo tempo em que ela está cada vez mais próxima das pessoas, devido principalmente ao desenvolvimento das telecomunicações, há um interdito sobre o tema que propicia um esvaziamento nas práticas rituais diante da morte, que podem ocorrer apenas de forma protocolar, sem possibilitar aos participantes a manifestação de sentimentos e o reconhecimento de seu luto, assim como o suporte social necessário em um momento de crise como esse. Seguimos, então, com as sessões nas quais são trabalhados os resultados.

\section{RITOS FÚNEBRES:AÇÃO E SÍMBOLOS}

Para definir ritual fúnebre, partiremos de uma definição encontrada na obra de Bayard (1996), intitulada: Sentido oculto dos ritos mortuários: Morrer é morrer?, que diz: "Todas as vezes que a significação de um ato reside mais em seu valor simbólico do que em sua finalidade mecânica, já estamos no caminho do procedimento ritual" (p. 7).

Rivière (1997, p. 30) traz uma definição para rito que nos será muito útil ao tratar de um tema tão complexo como o dos rituais fúnebres (discutiremos a relação entre as palavras rito e ritual mais adiante). Segundo ele:

(...) os ritos devem ser sempre considerados como conjunto de condutas individuais ou coletivas, relativamente codificadas, com um suporte corporal (verbal, gestual, ou de postura), com caráter mais ou menos repetitivo e forte carga simbólica para seus atores e, habitualmente, para suas testemunhas, baseadas em uma adesão mental, eventualmente não conscientizada, a valores relativos a escolhas sociais julgadas importantes e cuja eficácia esperada não depende de uma lógica puramente empírica que se esgotaria na instrumentalidade técnica do elo causa-efeito.

Desse modo, a palavra ritual diz respeito ao sentido daquilo que é ritualístico ou que tem propriedades rituais. Esta palavra alude ao sentido daquilo que é ritual, como uma qualidade de um ato que se prolonga para além do ato em si e adquire características simbólicas. Assim, como 
encontramos em Bayard (1996), o rito fúnebre é, a princípio, o gesto técnico de lavar, enterrar e cremar o cadáver, mas é o seu prolongamento para ato simbólico que o torna abrangente em todo o seu sentido.

Os rituais, portanto, vão além da ação e são repletos de símbolos. Esses símbolos podem ter vários significados e possibilitam descrever o que não conseguimos expressar em palavras. Visto a partir de seu interior simbólico, o ritual pode ser entendido como um sistema de intercomunicação simbólica entre o nível do pensamento cultural e seus complexos significados, a ação social e o acontecimento imediato (Krom, 2000). Desta forma, a capacidade que o ritual tem de funcionar como sistema de intercomunicação entre estrutura e significado lhe confere forte poder transformador, pois, à medida que transmite um significado ao longo das gerações, possibilita a formação de novas concepções de mundo (Krom, 2000).

As cerimônias são, por conseguinte, como as etapas de um ciclo que desejamos marcar e revelar, uma espécie de moldura que determina, circunscreve e torna consciente desde o quadro mais banal ao mais cruel. Como destaca
Roberto da Matta, na apresentação da obra Os Ritos de Passagem, de Van Gennep, o rito enquadra em sua coerência cênica o que se encontra além da realidade e da concretude do mundo cotidiano, sugerindo ou insinuando a esperança de todos os homens: "na sua inesgotável vontade de passar e ficar, de esconder e mostrar, de controlar e libertar, nesta constante transformação do mundo e de si mesmo que está inscrito no verbo viver em sociedade" (Gennep, 1978, p. 11).

Para Bayard (1996), os ritos fúnebres têm início com a agonia e coincidem com a fase inicial do luto. O segmento se dá com o velório, as exéquias, as condolências e o luto público (para pessoas de destaque), social (como no caso do uso de cor específica de roupa) e psicológico (o sentimento da perda), prolongando-se com o culto dos mortos ou a visita ao cemitério, como ocorre no dia de finados. Ele distingue os ritos de oblação, em que há solicitude e delicadeza com o defunto, como, por exemplo, a toalete mortuária, e os ritos de passagem, nos quais há a consagração da separação entre o morto e os vivos, assegurando a inclusão do morto em um estatuto post mortem [grifos nossos].

\section{RITO E RITUAL: SOBRE SIGNIFICADOS}

Sobre essa questão do significado dos termos, Rivière (1997) nos diz que na tradição francesa ${ }^{1}$ os termos rito e ritual possuem zonas semânticas vizinhas que apresentam fronteiras indeterminadas e interpenetrações recíprocas, a ponto de virem mesmo a se tornar muitas vezes palavras sinônimas. Ao longo dos séculos, os significados desses dois termos se confundiram, tanto que, segundo este autor, é inútil procurar no século XX uma distinção, tanto em francês quanto em inglês, para as palavras rito e ritual.

Porém, parece ser possível identificar a diferença de significado entre as duas palavras, embora essa diferença seja sutil. Concordamos com Dornelles (2002), o qual mostra como o ritual parece consistir em um conjunto de ritos, enquanto rito parece ser a unidade formadora do processo ritual. A definição dada pelo dicionário Aurélio para as palavras rito e ritual também parecem confirmar a diferença existente entre os dois termos, apesar de em certos momentos parecerem muito similares, ou mesmo sinônimos.

De acordo com Ferreira (2003, p. 483), a definição para Rito é a seguinte: "As regras e cerimônias próprias da prática de uma religião"; enquanto isso, Ritual é definido como: "Relativo a rito(s)".

A diferença é sutil, pois ritual é descrito como sendo relativo a rito ou ritos (no plural), o que é significativo, visto que um ritual pode ser composto por vários ritos, sendo, portanto, referente a estes e abrangendo os mesmos, pois de acordo com o dicionário, um termo é relativo quando se

1 O estudo do ritual possui tradição antropológica e remonta ao surgimento da Antropologia, que se deu na Europa. refere a uma palavra ou sentido anterior. Portanto, a palavra ritual refere-se a uma palavra ou sentido anterior, ou seja, refere-se à palavra rito, abrangendo-a.

Neste sentido, podemos compreender que cada processo ritual de movimentação entre posições, estados, status ou condição do indivíduo ou do grupo social transitante entre tais posições pode ser mais ou menos longo, com vários estágios (ritos) e, portanto, com passagens que vão de cada um desses estágios para o seguinte, na ordem processual estabelecida.

Devemos observar, por exemplo, que Gennep (1978) intitula seu livro de: Os Ritos de Passagem, utilizando a palavra rito e não ritual, o que também ocorre na denominação do livro de Bayard (1996), cujo título é: Sentido oculto dos ritos mortuários. Outro autor que intitula seu livro utilizando o termo rito é Rivière (1997): Os ritos profanos. Por outro lado, confirmando o sentido de ritual como um processo, um livro de Turner (1974), O Processo Ritual, utiliza não mais o termo rito, mas ritual, porque agora o título se refere ao processo maior e não mais aos membros componentes (ritos) do processo como um todo, aparecendo a palavra rito no decorrer do livro referindo-se às várias manifestações sociais dos povos estudados pelo autor.

Neste estudo, estamos utilizando a palavra ritual por considerá-la mais abrangente. Porém, consideramos para a pesquisa todos os trabalhos que tratam do tema, tanto com a palavra ritual como com a palavra rito, pois nos interessa aqui estudar o sentido daquilo que é ritualístico, ou seja, que possui propriedades rituais, não sendo objeto desta pesquisa o desvendamento das aproximações semânticas 
ou das diferenças de significado. Esta breve explanação serve apenas para efeito de compreensão, já que vemos as duas palavras sendo utilizadas na literatura, e também para justificar nossa opção pela palavra ritual.

Do mais, tendo já abordado a compreensão do que é ritual fúnebre, faz-se necessário elaborar também, neste momento, uma compreensão acerca da escolha da palavra fúnebre em detrimento de outras palavras como: Funerário, Funéreo ou Mortuário que, de acordo com o Dicionário Aurélio (Ferreira, 2003), significam fúnebre. Para a palavra fúnebre, esse dicionário traz a seguinte definição: relativo à morte, aos mortos ou a coisas a eles relacionadas; funerário, funeral, funéreo, mortuário. Portanto, de todas as palavras listadas, a palavra fúnebre é a mais completa, abrangendo as outras.

\section{O SENTIDO DE PASSAGEM NO RITUAL}

A vida de qualquer sociedade funda-se na passagem entre posições, estados e status. Compreende-se que os indivíduos modificam-se ao atravessarem a fronteira de cada etapa e nisso se assemelham as cerimônias de nascimento, infância, puberdade, noivado, casamento, gravidez, paternidade, iniciação religiosa e funerais, sendo importantes também as passagens de uma estação a outra, de um ano a outro etc. (Gennep, 1978).

Gennep (1978) assinala a existência de Ritos de Passagem, que se decompõem em: Ritos de Separação (preliminares), Ritos de Margem (liminares) e Ritos de Agregação (pós-liminares), sendo que, dependendo das características referentes a cada cerimônia, todas podem aparecer ou uma pode ser mais evidente. Assim, o noivado corresponde à margem entre a adolescência e o casamento, implicando ritos de separação, de margem e de agregação à margem. $\mathrm{O}$ casamento implica a separação da margem, aparecimento de uma nova e a agregação à situação de casado, sendo que no casamento encontram-se mais presentes os ritos de agregação, da mesma forma que em cerimônias fúnebres se evidenciam os ritos de separação [grifos do autor].

Augras (1984) explica que é como se a vida humana fosse repleta de momentos não necessariamente ligados e cheia de falhas, como em um caminho com obstáculos a serem ultrapassados, cabendo ao ser humano criar continuidade. $\mathrm{O}$ homem cria o caminho e estabelece ligação entre as partes. É o próprio homem que faz a ponte que traz continuidade à vida e se transforma na ponte ou na porta por onde se dará a passagem.

A simbologia da ponte aparece, por exemplo, na denominação do Papa como o Sumo Pontífice, do latim Pontifex, aquele que faz a ponte, ou seja, para aqueles que compartilham a crença católica, o Papa é investido do mais alto poder de estabelecer a comunicação entre este mundo e o outro (divino, sobrenatural) e é investido do maior poder de estabelecer a passagem entre esses dois mundos. Segundo Augras (1984), na Bíblia cristã, a simbologia da porta como passagem aparece nas palavras de Cristo quando ele diz que é a porta, e quem entrar por ele será salvo.

Para Augras (1984), falar de passagem é falar de movimento, de uma imagem altamente espacial, no qual os estados anterior e posterior à passagem são sempre delimitados simbolicamente e a passagem entre eles é permeada por perigos que, apesar de geradores de tensão, têm de ser ultrapassados, sendo também a passagem para a preparação para uma nova vida, que sempre é melhor.

Tal movimento se dá em um tipo de tempo com forte conteúdo simbólico, denominado na Antropologia de tempo estrutural, relativo a "um tempo social, fortemente ligado à experiência vital e à visão de mundo de uma sociedade ou civilização" (Cavalcante, 1999, p. 77). Nesse tempo estrutural, o ritual (neste caso, o ritual fúnebre) transcende o tempo real da morte já ocorrida para que possa haver um reconhecimento social desta, ou seja, o morto precisa morrer também socialmente. Turner (1974) faz referência ao tempo estrutural quando utiliza os termos estrutura e anti-estrutura, sendo o tempo estrutural estável e a anti-estrutura dotada da instabilidade do limiar, o período de ruptura da continuidade da vida social.

Sobre isso, Turner (1974) formula a hipótese segundo a qual a manutenção de uma ordem social pressupõe momentos de suspensão durante os quais se desenvolve o drama social que vai remanejar os indivíduos (os vivos e os mortos) entre posições, através dos ritos de passagem. O ritual para este autor representa uma dramatização para resolver uma crise da ordem social, uma forma de manejar as mudanças e conflitos. Para que o conflito da realidade social - cindida pelas mudanças (das quais a morte representa um conflito extremo) -, possa ser resolvido, é necessário que tal crise seja não somente definida de forma objetiva (narrada), mas é indispensável que ela seja vivida emocionalmente.

\section{OS RITUAIS E SUAS FUNÇÕES NO PROCESSO DE LUTO}

Luto, de acordo com o dicionário Aurélio (Ferreira, 2003), significa tanto o sentimento de dor pela morte de alguém quanto os sinais exteriores deste sentimento, em especial o traje usado e o tempo de permanência em estado de luto. É considerado reação normal e esperada frente ao rompimento de uma relação significativa, pois se compreende que ocorre não simplesmente uma morte, mas a partida de alguém amado em circunstância dolorosa (Schlindwein, 2001). 
No que diz respeito ao(s) significado(s) presente(s) em rituais fúnebres, podemos considerar que incluem a demarcação de um estado de enlutamento, de reconhecimento da importância da perda e da importância daquele ente que foi perdido. Ritualizar é marcar, pontuar um aspecto da realidade ou um acontecimento. Neste contexto, os enlutados tendem a se encontrar em um estado de margem ou limiar, no qual entram mediante ritos de separação do morto e saem através de ritos de suspensão do luto e reintegração social. Algumas vezes coincide o período de margem dos vivos com o período de margem do morto (Gennep, 1978), ou seja, o término do período de luto coincide com a agregação do morto em um estatuto post mortem, de acordo com a crença de cada cultura.

Os rituais relacionados com a morte, como os funerais, servem para contextualizar a experiência, permitindo as mudanças de papéis e a transição do ciclo de vida. Além do mais, podem oferecer à família o suporte da sensação de pertencer a uma cultura capaz de proporcionar respostas previsíveis num momento em que o choque da perda deixa-a entorpecida e desarticulada. Desta maneira, a universalidade das manifestações humanas diante da morte existe para atender às necessidades psicológica e social de dar um enquadramento e uma previsibilidade à perda pela morte (Bromberg, 2000).

Bromberg (2000) destaca que, por conterem recursos como os de familiarização, repetição e transformação, as experiências rituais têm se revelado significativas nas transições do ciclo de vida, permitindo o estabelecimento de um elo entre passado e futuro, por incorporarem significados tanto da família quanto da cultura.

Bromberg (2000, p.112) pontua que o uso de rituais como recurso terapêutico envolve três aspectos:

- Um ritual para admitir a perda e entrar no luto;

- Um ritual que simbolize o que os familiares incorporaram do morto;
- Um ritual para simbolizar os momentos de mudança na vida.

Para Imber-Black (1998), os rituais de luto apresentam como funções: marcar a perda de um dos membros da família; afirmar a vida como foi vivida pelo que morreu; facilitar a expressão do luto conforme os valores da cultura; falar sobre a morte e sobre a vida que continua expressando significados; apontar uma direção que faça sentido diante da perda e da continuação da vida dos que ficaram.

Esta função do ritual também é compartilhada por Herouet (2013) ao ressaltar que, apesar de a cerimônia ser, a priori, em homenagem ao morto, a vida continua é para os vivos, sendo o ritual, portanto, especialmente vital e benéfico para aqueles que assistem, criando um momento de comunhão, de estar juntos, de cumplicidade, de compaixão e renovação, estabelecendo conexão com o sagrado e marcando o início do luto necessário. Desta forma, é importante garantir um tributo digno ao falecido em uma cerimônia para marcar este momento, estabelecendo uma reintegração do defunto em outro lugar, que é o da memória.

Compreende-se, a partir de todas as considerações feitas, que o caráter simbólico dos rituais, incorporados pelos indivíduos, tende a permitir ou facilitar a comunicação social de significados relacionados à morte e o morrer, fornecendo sentido à realidade. Os rituais podem ajudar a simbolizar a morte do ente querido, favorecendo a reintegração cotidiana e social rompida pela mudança que a perda ocasiona. Além do mais, o investimento e dedicação presentes nos rituais poderão amenizar possíveis sentimentos de culpa, sendo o ritual fúnebre necessário para a maturação psicológica, por ter atribuições relevantes como: ajudar o indivíduo a confrontar-se com a perda concreta, entrando no processo de luto, possibilitando-lhe também a manifestação pública de seu pesar.

\section{SIGNIFICAR A PERDA NA SOCIEDADE DO INTERDITO DA MORTE}

A literatura tem mostrado que vem ocorrendo mudança na forma como tem sido tratado o tema da morte ao longo do tempo nas sociedades ocidentais, de modo que vários autores (Ariès, 2003; Cunha, 1999; Deweik, 2007; Gorer, 1955; Imber-Black, 1998; Kovács, 1992, 2003, 2005; Kübler-Ross, 1987; Maranhão, 1987; Mitford, 1963; Veras \& Soares, 2016) têm ressaltado um progressivo distanciamento das questões relativas à finitude no que diz respeito à sociedade de um modo geral, mesmo considerando que a morte encontra-se cada vez mais escancarada e maciçamente veiculada nos meios de comunicação.

Há um paradoxo implicado no tema da morte nos dias atuais, pois ao mesmo tempo em que ela está cada vez mais próxima das pessoas, devido principalmente ao desenvolvimento das telecomunicações, há um interdito sobre o tema. Neste contexto, observamos que a televisão introduz diariamente em milhares de lares cenas de morte e todo tipo de violência, acidentes e doenças sem, no entanto, haver possibilidade de que esse conteúdo seja elaborado (Kovács, 2005). A morte torna-se, então, ao mesmo tempo, companheira cotidiana e interdita. Apesar de tão próxima, invasiva e sem limites, "reina uma conspiração do silêncio" (Kovács, 2005, p. 486).

Assim, apesar da facilidade de acesso ou mesmo do escancaramento de notícias sobre mortes e imagens de mortos, Veras e Soares (2016) sinalizam que permanece o enquadramento da morte como tema tabu, de forma que apenas delimitaram-se lugares para ela, que são: o lugar do espetáculo; o lugar do produto; da técnica; da banalização ou mesmo do humor, como em determinadas propagandas de 
funerárias que fazem trocadilhos referentes à morte. Desta maneira, continua vedado socialmente o aprofundamento em questões ligadas, por exemplo, à expressão de sentimentos de dor e pesar diante da morte de um ente querido, ou às demandas existenciais relacionadas à própria finitude.

Nesse contexto de negação, muitas vezes os rituais que são praticados diante da morte parecem se esvaziar, ocorrendo apenas de forma protocolar, sem possibilitar aos participantes a manifestação de sentimentos, o reconhecimento de seu luto e o suporte social necessário em um momento de crise como esse. Imber-Black (1998) alerta que os rituais de luto podem ocorrer de forma rígida ou vazia, deixando as pessoas desconectadas de qualquer sensação de elaboração genuína, porque "a falta de rituais de luto autênticos na vida contemporânea frequentemente impede o processo necessário de elaboração após uma morte" (p. 230).

Como já dissemos, quando o ritual é dotado de seu caráter simbólico de recomhecimento da perda, tende a ajudar a simbolizar a morte do ente querido, favorecendo a reintegração cotidiana e social rompida pela mudança que a perda ocasiona. Porém, o ritual somente consegue cumprir essa função se houver um envolvimento, uma espécie de adesão mental dos participantes, que devem se identificar com o ritual e com grupo que participa dele. Quando não há essa adesão, ocorre um esvaziamento do sentido da prática ritual, que pode se dar tanto para o grupo todo como para algum ou alguns participantes individualmente. Cunha (1999) fez uma distinção interessante entre rituais que confortam e rituais que perturbam. De acordo com ela, quando o ritual é despido de sua dimensão simbólica apaziguadora, momentos como do funeral tendem a perturbar e não confortar.

Sobre essa questão, Deweik (2007) traçou um paralelo entre o afastamento para com o tema da morte e a depressão. Para ele, em uma cultura que gira em torno de um individualismo exacerbado e hedonista, no qual os avanços tecnológicos ditam os preceitos de um modo de vida no qual morrer é um acidente de percurso, o adoecimento psíquico é uma forma de burlar o interdito, lembrando o homem de sua morte.

O deprimido seria, então, um indivíduo que denuncia em seu próprio padecer que a morte é inerente à vida, visto que o sofrimento condensa essa condição básica, que apresenta a infelicidade como um subproduto do que tem sido silenciado (Deweik, 2007). Para este autor, diferente do medo da putrefação e do horror diante da decomposição, o medo contemporâneo assume a forma de uma vergonha; antigamente prevaleciam os rituais, mas agora resta um silenciar dos costumes.

Segundo Maranhão (1987), a morte vem se tornando cada vez mais vergonhosa e interdita, ocorrendo um fenômeno curioso na sociedade capitalista, que é a substituição da interdição em torno do sexo pela interdição em torno da morte, ou seja, vem ocorrendo uma inversão na qual a obscenidade não reside mais nos fatos referentes ao início da vida, mas sim aos referentes ao seu fim.

\section{CONSIDERAÇÕES FINAIS}

A devoção nos cuidados com o cadáver e os critérios muitas vezes longos e minuciosos seguidos em rituais fúnebres revelam a inquietação que a morte provoca e a tentativa de encontrar um lugar em nossas vidas para algo que ainda se encontra além de uma explicação. A morte é algo diante do qual ficamos perplexos, porque representa o desconhecido na existência humana. Além do mais, a morte do outro nos remete a nossa própria morte. Criamos, então, formas de lidar com essa realidade; acreditamos que existe outra vida depois da morte, praticamos rituais diante da perda de um ente querido, dedicamo-nos ao corpo morto e o honramos e choramos. Criamos um espaço sagrado dentro de nossas vidas para algo que vai além das explicações palpáveis.

Portanto, o caráter simbólico dos rituais, incorporados pelos indivíduos, comunica socialmente e fornece sentido à realidade, ajudando a simbolizar a morte do ente querido, visto que se trata de um momento extremamente doloroso e de difícil aceitação. Diante do desprazer que a morte provoca, o acontecimento torna-se mais acessível de ser trabalhado em nossa consciência quando nos são fornecidos símbolos que nos ajudam na passagem por essa fase difícil e na reintegração cotidiana e social rompida pela mudança que a perda ocasiona.

A compreensão do ritual fúnebre como importante categoria de análise nas condições de luto implica, portanto, que haja mais subsídios teóricos que contribuam com a fundamentação das práticas de suporte aos enlutados, sendo estas práticas pensadas como medidas preventivas diante da possibilidade de complicações em estados de luto, como o luto crônico, o luto adiado, transtornos psiquiátricos ou manifestações psicossomáticas.

Compreende-se, portanto, que a dedicação presente nos rituais relacionados à morte possibilita aos vivos amenizar possíveis sentimentos de culpa, sendo o ritual fúnebre necessário para a maturação psicológica por ter atribuições relevantes, como ajudar o indivíduo a confrontar-se com a perda concreta, entrando no processo de luto e possibilitandolhe também a manifestação pública de seu luto.

Deste modo, considerando-se a relevância das manifestações rituais diante da morte, bem como a carência de estudos acerca da relação entre rituais e luto, sugere-se a necessidade de estudos sobre o tema, principalmente no que se refere às características do mundo contemporâneo. 


\section{REFERÊNCIAS}

Ariès, P. (2003). História da morte no ocidente: Da Idade Média aos nossos dias. Rio de Janeiro: Ediouro.

Augras, M. (1984). Passagem: Morte e renascimento. In H. Passos, D. Pitta, \& R. Motta (Eds.), O Imaginário e a Simbologia da Passagem. Recife: Massangana.

Bayard, J. P. (1996). Sentido oculto dos ritos mortuários: Morrer é morrer? São Paulo: Paulus.

Bromberg, M. H. (2000). A Psicoterapia em situações de perdas e luto. Campinas: Livro Pleno.

Cavalcante, M. L. (1999). O rito e o tempo: A evolução do carnaval carioca. In M. L. Castro, O rito e o tempo: Ensaios sobre o carnaval. Rio de Janeiro: Civilização Brasileira.

Cunha, V. (1999). A morte do outro: Mudança e diversidade nas atitudes perante a morte. Sociologia, Problemas e Práticas, $31,103-128$.

Deweik, M. (2007). Para viver a morte: Do medo à negação, muitas são as formas de encará-la. Mas será que hoje este assunto ainda é permitido? Psique: Ciência e Vida, 2(22), 42-43.

Dornelles, J. (2002). O rito na análise antropológica. Recuperado de http://www.megabaitche.htp.ig.com.br/jonatas/rito.html

Ferreira, A. B. (1993). Minidicionário Aurélio da Lingua Portuguesa ( $3^{\text {a }}$ ed.). Rio de Janeiro: Nova Fronteira.

Gennep, A. V. (1978). Os ritos de passagem. Rio de Janeiro: Vozes.

Gorer, G. (1955). The pornography of death. Encounter, 5(4), 49-52.

Herouet, R. (2013). Rites et rituels funéraires: Fonctions, objectifs, bénéfices. Recuperado de http://www.geneasens.com/ dictionnaire/rites_et_rituels_fun $\% \mathrm{C} 3 \% \mathrm{~A} 9 \mathrm{raires} . \mathrm{html}$
Imber-Black, E. (1998). Os rituais e o processo de elaboração. In F. Walsh \& M. McGoldrick, Morte na familia: Sobrevivendo às perdas (pp. 229-245). Porto Alegre: Artmed.

Kovács, M. J. (1992). Morte e desenvolvimento humano. São Paulo: Casa do Psicólogo.

Kovács, M. J. (2003). Educação para a morte: Temas e reflexões. São Paulo: Casa do Psicólogo.

Kovács, M. J. (2005). Educação para a morte. Psicologia, Ciência e Profissão, 25(3), 484-497.

Kübler-Ross, E. (1987). Sobre a morte e o morrer ( $3^{\mathrm{a}}$ ed.). São Paulo: Martins Fontes.

Leakey, R. (1997). A origem da espécie humana. Rio de Janeiro: Rocco.

Maranhão, J. L. (1987). O que é morte ( $3^{\mathrm{a}}$ ed.). São Paulo: Brasiliense.

Mitford, J. (1963). The american way of death. Nova York: Vintage Books.

Rivière, C. (1997). Os ritos profanos. Petrópolis: Vozes.

Schilindwein, R. (2001). Aspectos psicológicos da terminalidade do luto e do morrer. Revista Científica em Psicologia, 1(1), 19-30.

Souza, C. P. (2008). Rituais fúnebres: Suas contribuições para a compreensão do processo de luto (Trabalho de Conclusão de Curso). Universidade Federal do Pará, Faculdade de Psicologia, Belém, PA, Brasil.

Turner, V. (1974). O processo ritual: Estrutura e anti-estrutura. Petrópolis: Vozes.

Veras, L., \& Soares, J. C. (2016). Aqui se jaz, aqui se paga: A mercantilização da morte. Psicologia \& Sociedade, 28, 226-236. 